\title{
Effect of food quality on carbon and nitrogen growth efficiency in the copepod Acartia tonsa
}

\author{
Ruth H. Jones ${ }^{1}$, Kevin J. Flynnn ${ }^{1, *}$, Thomas R. Anderson ${ }^{2}$ \\ ${ }^{1}$ Ecology Research Unit, School of Biological Sciences, University of Wales Swansea, Singleton Park, Swansea SA2 8PP, \\ United Kingdom \\ ${ }^{2}$ George Deacon Division, Southampton Oceanography Centre, European Way, Southampton SO14 3ZH, United Kingdom
}

\begin{abstract}
Populations of the copepod Acartia tonsa were fed a mixture of algal prey (diatom Thalassiosira weissflogii, prymnesiophyte Emiliania huxleyi, dinoflagellate Aureodinium [Gymnodium] pigmentosum) supplied at saturating concentrations, grown under either nitrogen-sufficient or nitrogen-deplete conditions, in order to study the impact of food quality on production and development throughout the life cycle of the copepod. Changes in predator population structure and biomass were recorded, along with consumption of each of the algal groups, permitting $\mathrm{C}$ and $\mathrm{N}$ growth efficiencies to be estimated. There was a clear difference in the Acartia tonsa population structure when fed $\mathrm{N}$-sufficient or $\mathrm{N}$-deplete prey, with those fed $\mathrm{N}$-deplete prey slower to develop and reproduce and laying fewer eggs. Algal nutrient status affected selectivity between the diatom and dinoflagellate, the latter being favoured under nutrient-deplete conditions, perhaps in part because their C:N ratio was less susceptible to altered nutrient status. There was no clear difference in the $\mathrm{N}$ growth efficiency (N-GE, typically $5 \%$ ) between $\mathrm{N}$-sufficient and $\mathrm{N}$-deplete prey, but certainly efficiency did not increase with $\mathrm{N}$-deplete prey. C growth efficiency (C-GE) declined from 5 to $2 \%$ with $\mathrm{N}$-deplete prey. However, while the ratio of N-GE:C-GE was clearly different between $\mathrm{N}$-sufficient (1) and N-deplete (2.5) treatments, actual growth efficiencies increased with time during the progression to later life history stages, culminating in highest efficiencies during active egg production. Caution should be exercised in assigning GE and predation rates in models incorporating zooplankton feeding on prey of variable nutrient status; these parameters are not constants and GE estimates from egg production experiments are likely to significantly overestimate efficiencies over the whole copepod life cycle.
\end{abstract}

KEY WORDS: Copepods · Food quality $\cdot$ Nutrient status $\cdot \mathrm{C}: \mathrm{N} \cdot$ Growth efficiency $\cdot$ Population $\cdot$ Life cycle

\section{INTRODUCTION}

Most models of heterotrophic activity assume a fixed growth efficiency (Frost 1993). For example, although the ecosystem model of Fasham et al. (1990) does not have an explicit parameter for zooplankton gross growth efficiency (GGE), the assumption is that a constant fraction of ingested material is utilised (converted into zooplankton biomass). For multinutrient models, the relative GGE value for each atomic constituent is governed by the stochiometric ratio of the elements in

${ }^{*}$ Corresponding author. E-mail: k.j.flynn@swansea.ac.uk the food versus that in the heterotroph (Anderson 1992, Anderson \& Hessen 1995). The limiting element (the one in shortest supply relative to demand) is used with a high and constant GGE, whereas excesses of non-limiting elements must be recycled. However, from a biological standpoint one may expect that the efficiency of retention of elements passing through a gut will vary not just with the stochiometric ratio but with the overall value of the food, including factors such as changes in protein, lipid, carbohydrate, and vitamin content (Checkley 1980, Nakano 1994, Sterner \& Hessen 1994). An organism supplied with poor food may be expected to be less fit and less efficient than one supplied with good food. A possible drawback of 
stoichiometric arguments is that they ignore the biochemical characteristics of food (Tang \& Dam 1999).

Copepods are important components of the marine food chain, especially as links between primary producers and fishes. The quality of the food available to them varies with the composition of the phytoplankton population and with the nutritional status of those populations (Parsons et al. 1984). Over recent years it has become apparent that mixed plankton diets are important (Kleppel 1993, Kleppel et al. 1998); while once diatoms were held to be good food items for copepods, there is increasing evidence that this is in fact not so (Kleppel 1993, Poulet et al. 1994, Miralto et al. 1999).

Here we report the results of a laboratory experiment designed to examine the effect of food quality, as defined by $\mathrm{N}$ : C ratio, of a mixed diet of phytoplankton on the growth rate and efficiency of the copepod Acartia tonsa. Prey were supplied at saturating concentrations to ensure that quality, not quantity, of food influenced production. Previous studies of copepod nutrition have focussed on the activity of adult stages and especially on egg production (Checkley 1980, Kiørboe 1989, Støttrup \& Jensen 1990). Our study is novel in that the effect of nutrition on growth through the whole life cycle was examined. Thus the implications for food quality for all stages from egg hatching, progression through instars, and ultimately to sexually active adults were determined.

\section{MATERIALS AND METHODS}

Prey. The prey species used were the diatom Thalassiosira weissflogii (Strain CCAP 1049, equivalent spherical diameter [ESD] 12 to $12.9 \mu \mathrm{m}$, grown on modified f/2 media as in Guillard \& Ryther [1962] but with $100 \mu \mathrm{M}$ nitrate), the dinoflagellate Aureodinium (Gymnodinium) pigmentosum (Strain CCAP 389, ESD 7 to $7.5 \mu \mathrm{m}$, grown on modified $\mathrm{K}$ media as in Keller et al. [1987] but with $100 \mu \mathrm{M}$ nitrate) and the prymnesiophyte Emiliania huxleyi (Strain L, NIOZ, Netherlands, ESD 3.8 to $4.1 \mu \mathrm{m}$, grown on modified $\mathrm{f} / 2$ media with $100 \mu \mathrm{M}$ nitrate). These species were chosen to enable simultaneous enumeration of all 3 organisms using an Elzone PC282 particle analyser. From previous feeding experiments, it had been determined that all 3 algae used in the experiments were freely consumed by all stages of Acartia tonsa. Algal cultures were grown at 18 to $19^{\circ} \mathrm{C}\left( \pm 1^{\circ} \mathrm{C}\right)$ and a photon flux density of around $180 \mu \mathrm{mol} \mathrm{m} \mathrm{m}^{-2} \mathrm{~s}^{-1}$, in a 12:12 h light:dark cycle, with nitrate (supplied at $100 \mu \mathrm{M}$ ) as the limiting nutrient. Cultures were discontinuous, being diluted either at a high or low rate, to maintain $\mathrm{N}$-sufficient or $\mathrm{N}$-deplete conditions respectively.
Predator and experimental procedure. The copepod Acartia tonsa was obtained from Environment \& Resource Technology (ERT) Orkney, UK. Stock populations were held in $5 \mathrm{l}$ glass bottles, gently aerated, and fed with a mixture of the 3 prey phytoplankton. For experimental studies, individual copepods, of the required stage, were picked out and placed in $200 \mathrm{ml}$ of medium $250 \mathrm{ml}$ tissue culture flasks and kept at 18 to $19^{\circ} \mathrm{C}\left( \pm 1^{\circ} \mathrm{C}\right)$. Two treatments with 2 replicates were run (Fig. 1). Prey were supplied in equal amounts, as judged from biovolume (which scales with $\mathrm{C}$ biomass assuming $200 \mathrm{~g} \mathrm{C} \mathrm{l}^{-1}$ : Wood \& Flynn 1995) in amounts that had previously been determined to be saturating. Thus, each copepod experimental flask was supplied with at least $5 \mathrm{nl}$ biovolume $\left(\sim 1 \mu \mathrm{g} \mathrm{C} \mathrm{ml}^{-1}\right)$ of each of the 3 algae. A gentle stream of air was supplied. Additional copepods of all stages were also removed and placed in tin capsules for determination of the initial $\mathrm{C}$ and $\mathrm{N}$ content. The daily experimental procedure was as follows:

Copepods were fed during the dark phase of the light:dark cycle. This was to minimise the change in nutritional status of $\mathrm{N}$-deplete phytoplankton when exposed to ammonium released by the copepods. At the beginning of each dark phase, approximately equal biovolumes of the 3 prey species were added to the copepod vessel and a $1 \mathrm{ml}$ volume withdrawn immediately to determine actual start (time, $t_{0}$ ) values of cell counts and biovolumes. Samples for determination of $\mathrm{CN}$ elemental composition were also taken for

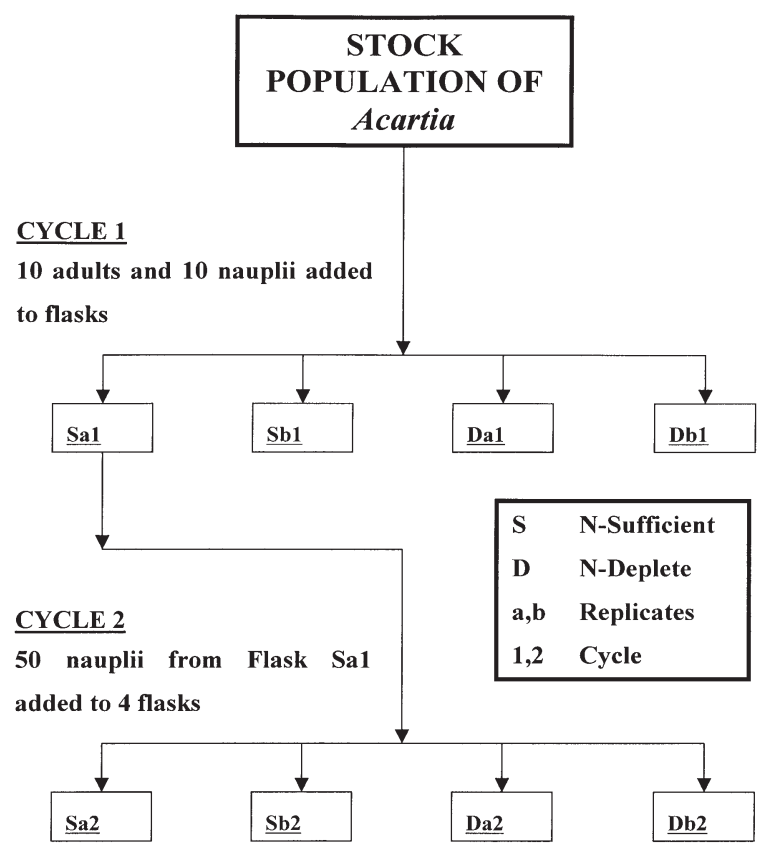

Fig. 1. Acartia tonsa. Schematic of methodology. Duration of Cycle 1 was $14 \mathrm{~d}$, and that of Cycle 2 was $11 \mathrm{~d}$ 
each prey species from their respective culture flasks; these were collected onto ashed $13 \mathrm{~mm}$ diameter glassfibre filters (Pall type A/E). After $12 \mathrm{~h}\left(t_{12}\right)$, the copepods were separated from the remaining prey using a $50 \mu \mathrm{m}$ aperture nylon mesh. The $t_{12}$ cell numbers and biovolume were determined for each prey species. The copepods, re-suspended in fresh particle-free seawater, were held without food in the light at $150 \mu \mathrm{mol} \mathrm{m}^{-2} \mathrm{~s}^{-1}$ for the following $12 \mathrm{~h}$ before again being fed at $t_{24}\left(=t_{0}\right.$ for the next cycle). To perform the experiment with a continual presence of food would have required a supply of algae every $12 h_{i}$ with 3 species of algae and the associated logistics, this was not possible. The maximum growth rate of Acartia tonsa grown on the $12 \mathrm{~h}$ feeding regime was no different (typical life cycle duration of ca. $11 \mathrm{~d}$ ) to that observed in stock cultures fed continuously.

Every 2 to $3 \mathrm{~d}$, the population structure (eggs, nauplii, copepodites and adults) of the copepods was determined at $t_{12}$ by counting them after they had first been filtered out gently using a $50 \mu \mathrm{m}$ mesh and suspended in a minimal amount of water under an Olympus SZ40 microscope. The copepods were then resuspended in the particle-free seawater as usual. At the end of the $14 \mathrm{~d}$ experimental period (Cycle 1), the final copepod population was enumerated and samples were taken for $\mathrm{CN}$ elemental analysis. From the population in a N-sufficient flask, a subset of nauplii was selected to start repeat flasks (Cycle 2: Fig. 1). Flasks were identified as ' $\mathrm{S}$ ' (fed with $\mathrm{N}$-sufficient prey) and ' $\mathrm{D}$ ' (fed with $\mathrm{N}$-deplete prey) in 1 of 2 replicates ('a' or ' $b$ ') and in the first (' 1 ') or second ('2') experimental cycle (e.g. 'Sa1' denotes $\mathrm{N}$-sufficient Replicate a during Cycle 1).

The CN elemental composition of the prey and the copepods were determined using Europa Scientific Roboprep and Tracermass instruments. Total C and N prey consumption by Acartia tonsa could therefore be calculated for each sampling interval. When combined with the biomass increase in the copepod population, estimated from the $\mathrm{C}$ and $\mathrm{N}$ content of different copepod stages plus the population structure measurements, the efficiency of conversion of prey $\mathrm{CN}$ into predator $\mathrm{CN}$ was calculated.

Growth efficiency calculations. A distinction must be drawn between the efficiency with which an individual zooplankter utilises food for growth during portions of its lifetime and the net efficiency with which a population uses substrates for production, taking into consideration processes such as mortality. The term 'gross growth efficiency', GGE, is usually defined as the proportion of ingested prey that is converted to predator biomass (Straile 1997). This efficiency has traditionally been computed from short-term experiments, and thus takes no account of natural mortality (i.e. death through old age or through errors of metabolism, as distinct from losses through predation). Over the longer term, material that is ingested and assimilated is lost not only through respiration (C) and regeneration $(\mathrm{N})$ but through other processes such as moulting and through natural mortality. In order to study population changes in response to food quality, we therefore define the efficiency with which a population of individuals converts food to biomass over time as the 'population growth efficiency', PGE. If mortality occurs during that period, then PGE will be less than GGE.

Here PGE is calculated as the change in predator biomass over a sampling interval divided by the total prey consumed. In order to calculate GGE it is necessary to know the total mortality that occurred and add that biomass to the measured living biomass at the end of the time interval. This sum is the total gross growth that occurred, which is then divided by the total prey consumed to give GGE. A numerical method was developed to calculate mortality during any given sampling interval ( $t$ to $t+1$ ) from the numbers of the different life history stages counted during each experiment. This method uses the following assumptions: (1) nauplii, copepodites and adults counted at time $t$ either remain unchanged, die, or progress 1 life history stage by time $t+1$ (i.e. within 2 to $3 \mathrm{~d}$ ); (2) eggs either progress to nauplii or suffer mortality during the time interval; (3) all eggs counted at time $t+1$ are produced during the time interval, and additionally extra eggs may be produced which progress to nauplii within the same interval. A series of calculations can then be undertaken to calculate mortality: (1) it is assumed that adults at time $t+1$ originate primarily from those present at time $t$, with any additional animals at time $t$ being lost as mortality and any shortfalls at time $t$ being compensated by progression of copepodites,

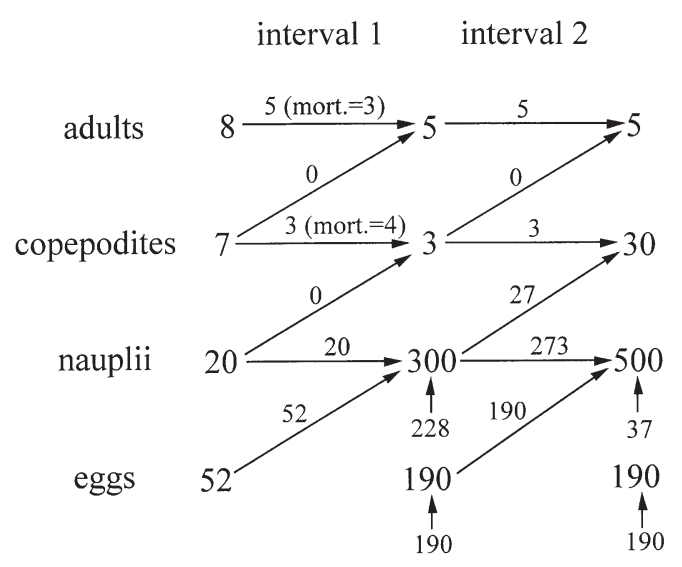

Fig. 2. Acartia tonsa. Example calculation of numbers of individuals between life history stages during 2 sampling intervals. Mortality (mort.) losses are indicated 


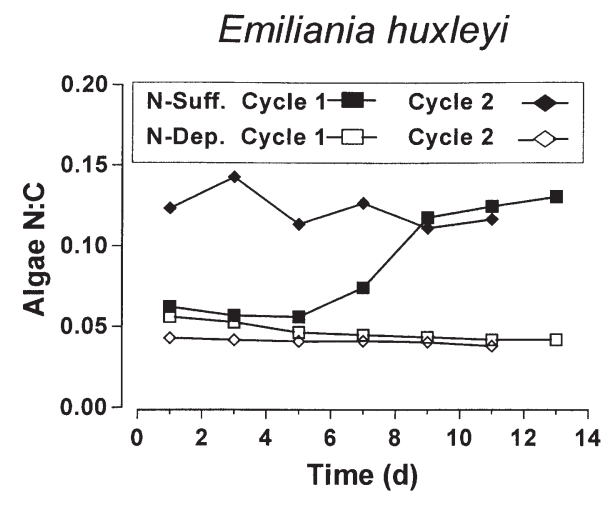

Thalassiosira weisflogii

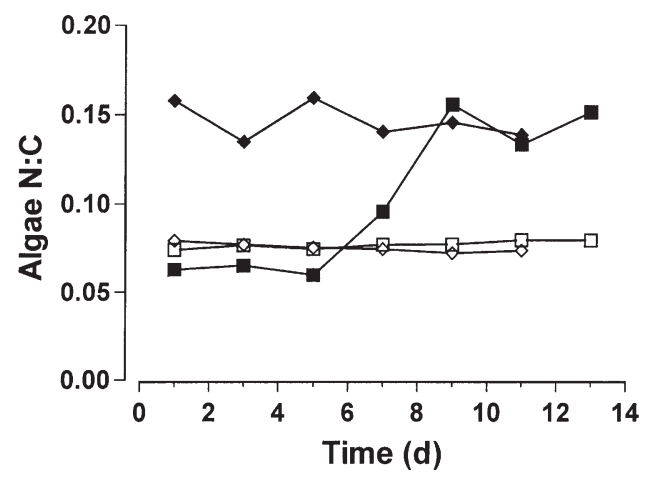

Aureodinium pigmentosum

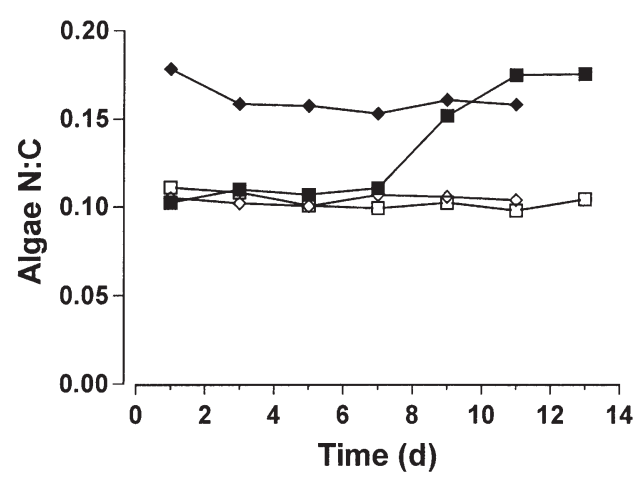

Fig. 3. N:C (mass) ratio for each prey species during the experimental cycles

permitting the progression of adults and copepodites from time $t$ to adults at $t+1$ to be calculatedi (2) taking into consideration copepodites which have been developed through to adults, the same calculation is repeated for progression of nauplii to copepodites, and eggs to nauplii; (3) the production of eggs and nauplii needed to make up numbers is calculated. An example of a resulting flowchart, taken from the experiment, is shown in Fig. 2. A computer program was written to perform the calculations.

\section{RESULTS}

\section{Composition of algae}

At the start of Cycle 1, all prey were $\mathrm{N}$-deplete; suspensions of prey destined to become $\mathrm{N}$-sufficient were diluted more rapidly and their $\mathrm{N}: \mathrm{C}$ increased until the prey fed to the N-sufficient flasks were all indeed N-sufficient by the end of the first week (Fig. 3). This allowed a period of acclimation for the copepods. Throughout Cycle 2 the N:C ratio of the prey was stable (Fig. 3).

\section{Copepod consumption of algae}

The amount of prey added was so calculated that the flasks contained a saturating level of food and that the

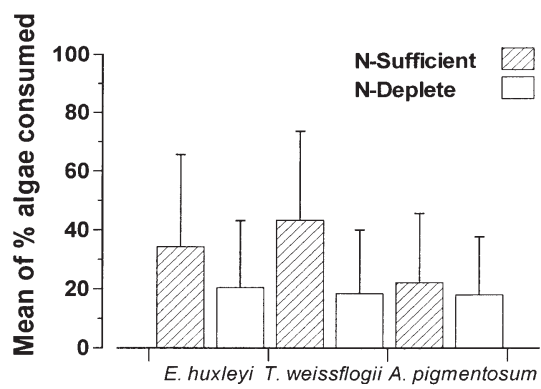

(a)

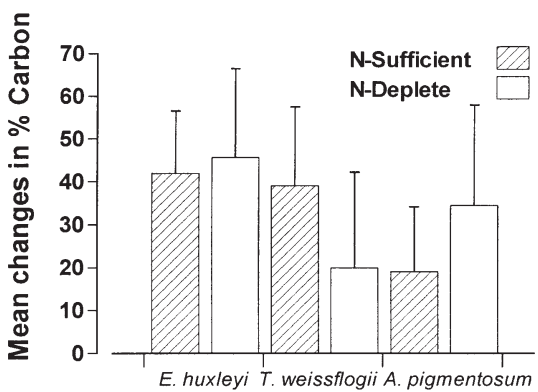

(b)

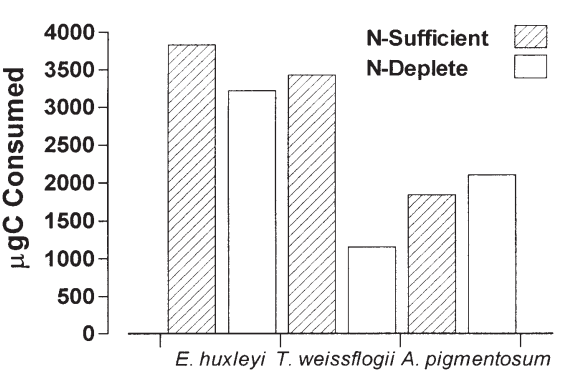

(c)

Fig. 4. Acartia tonsa. Summaries of prey consumption over the 2 experimental cycles. (a) Mean percentage of each prey used per day showing that no prey item became limiting; (b) mean change in contribution of each prey to daily consumption showing change in choice of prey species; (c) total cumulative $\mathrm{C}$ consumed per suspension volume for each prey. Bars in (a) and (b) indicate standard deviation. Full specific names are given in Fig. 3 
Table 1. Acartia tonsa. Average $\mathrm{C}$ and $\mathrm{N}$ values of the different copepod stages. A constant C:N of 6.185 was assumed (averaged from all C:N analyses, see 'Results')

\begin{tabular}{|lrrrrr|}
\hline Stage & $\mu \mathrm{gC}$ & $\begin{array}{c}\text { No. } \\
\text { sampled }\end{array}$ & SD & C:N & $\mu g \mathrm{~N}$ \\
\hline Adults & 2.8027 & 50 & 0.5216 & 6.185 & 0.4531 \\
Copepodites & 0.8351 & 50 & 0.6381 & 6.185 & 0.1350 \\
Nauplii & 0.1138 & 110 & 0.0780 & 6.185 & 0.0184 \\
Eggs & 0.0536 & 60 & 0.0463 & 6.185 & 0.0087 \\
\hline
\end{tabular}

copepodites. By Day 11, the enhanced status of Sa2 and Sb2 over their N-deplete controls was indisputable (Fig. 5; note difference in the $y$-axis scales).

For the calculation of predator biomass, we had estimated average $\mathrm{C}$ and $\mathrm{N}$ values of the different copepod stages (Table 1). The values for the $\mu \mathrm{gC}$ of the nauplii and eggs were checked using the estimated volume and assuming $1 \mathrm{l}=200 \mathrm{gC}$ (the C-density of similar-sized phytoplankton cells: Wood \& Flynn 1995). This assumption showed that the values used (Table 1) were reasonable. The value of $0.0536 \mu \mathrm{g} C$ for the eggs copepods never ran out of prey; the maximum consumed was $70 \%$ of the added prey (Fig. 4a). The percentage of algae consumed, judged from biovolume, was significantly greater $(p=0.0042)$ in the flasks under $\mathrm{N}$-sufficient conditions than in those under N-deplete conditions. This was particularly apparent for Emiliania huxleyi and Thalassiosira weissflogii. Fig. $4 \mathrm{~b}$ presents the percentage composition of prey consumption, showing that $\mathrm{N}$-deplete $T$. weissflogii were the leastfavoured prey. Fig. 4c shows the cumulative consumption of prey-C. The dinoflagellate Aureodinium pigmentosum was consumed at similar rates whether it was $\mathrm{N}$-deplete or $\mathrm{N}$-sufficient. As evidenced in Fig. $4 \mathrm{~b}$, the diatom T. weissflogii was least favoured when $\mathrm{N}$-deplete, with the prymnesiophyte E. huxleyi at an intermediate position.

Coupled with these differences in diet quality and consumption were significant differences in the development of the copepod populations (Fig. 5). At the start of Cycle 1, each of the 4 flasks contained 10 adults and 10 nauplii, all initially fed with N-deplete prey, half of which were gradually phased to N-sufficient prey (cf. Fig. 3). There was considerable variation between replicates, but $\mathrm{Sa} 1$ and $\mathrm{Sb} 1$ developed much more rapidly than the control, N-deplete (Da1 and Db1) flasks. Adults in the populations fed $\mathrm{N}$-deplete algae for the entire $2 \mathrm{wk}$ period were slower to develop and laid fewer eggs. Flasks for Cycle 2 were each started with 50 nauplii from Flask Sb1 and were fed $\mathrm{N}$-sufficient or $\mathrm{N}$-deplete prey from the first day. It was clear even by Day 4 of Cycle 2 that the development of the instars fed $\mathrm{N}$-sufficient prey was more advanced, with a greater proportion of
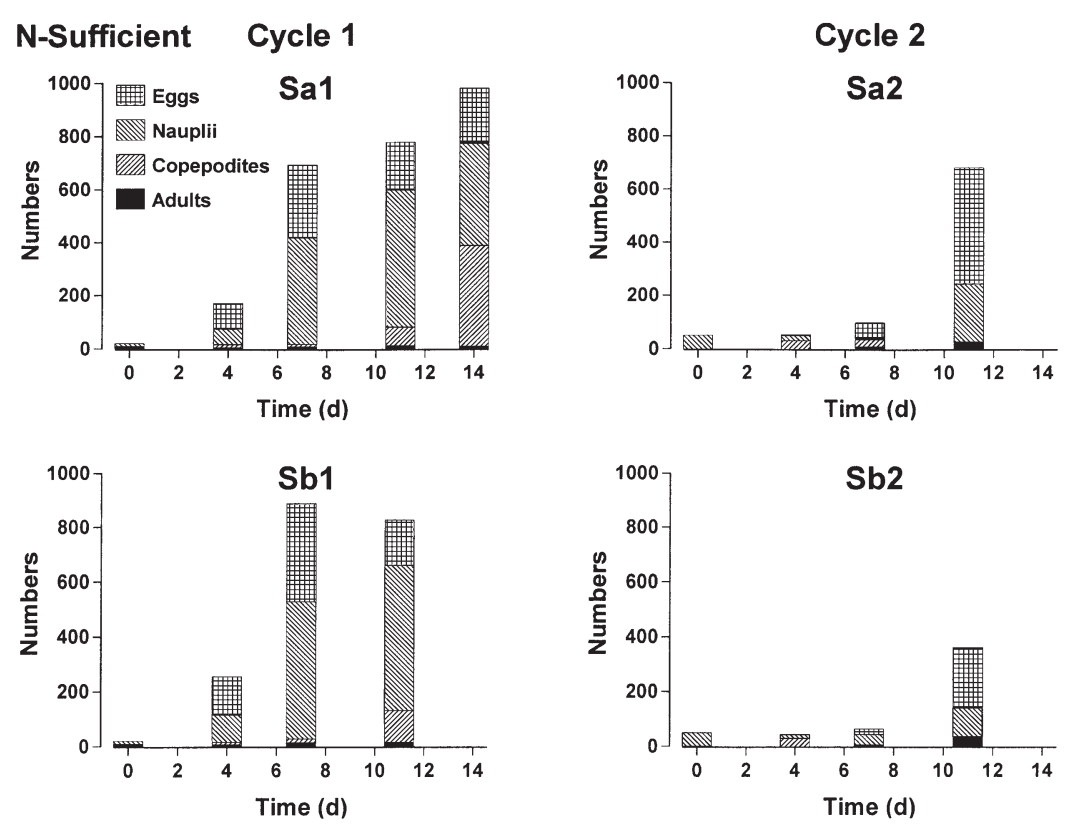

\section{N-Deplete}
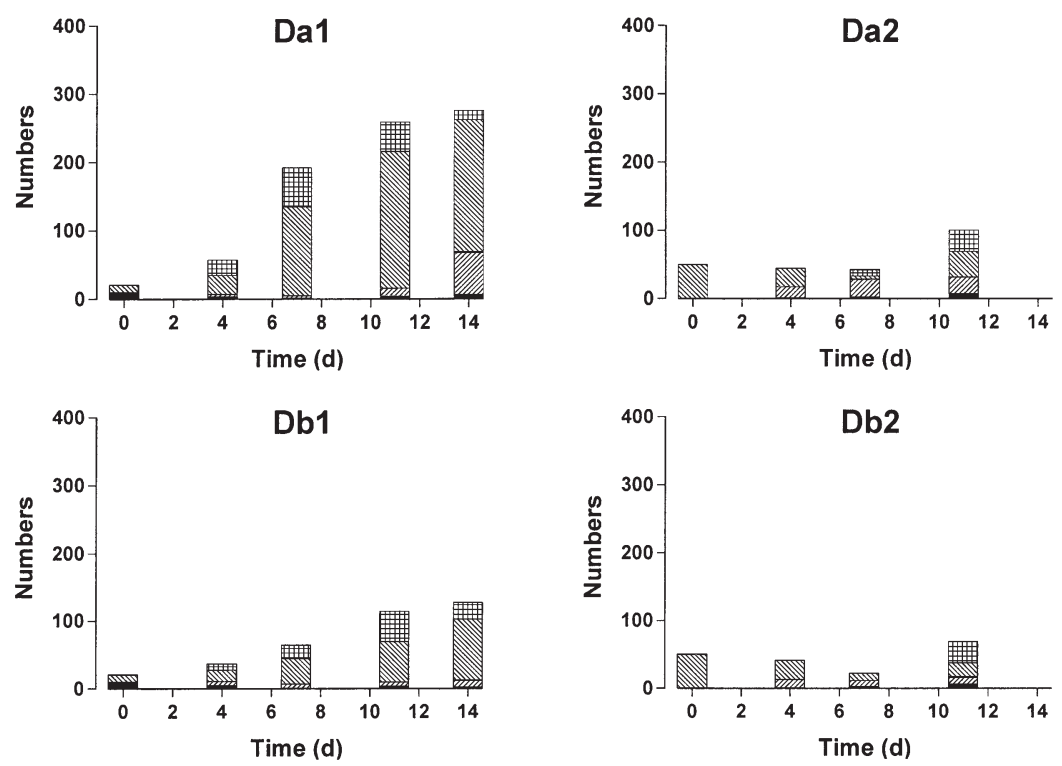

Fig. 5. Acartia tonsa. Change in population structure during experimental cycles. Note the difference in the $\mathrm{y}$-axis scale between $\mathrm{N}$-sufficient and $\mathrm{N}$-deplete treatments 

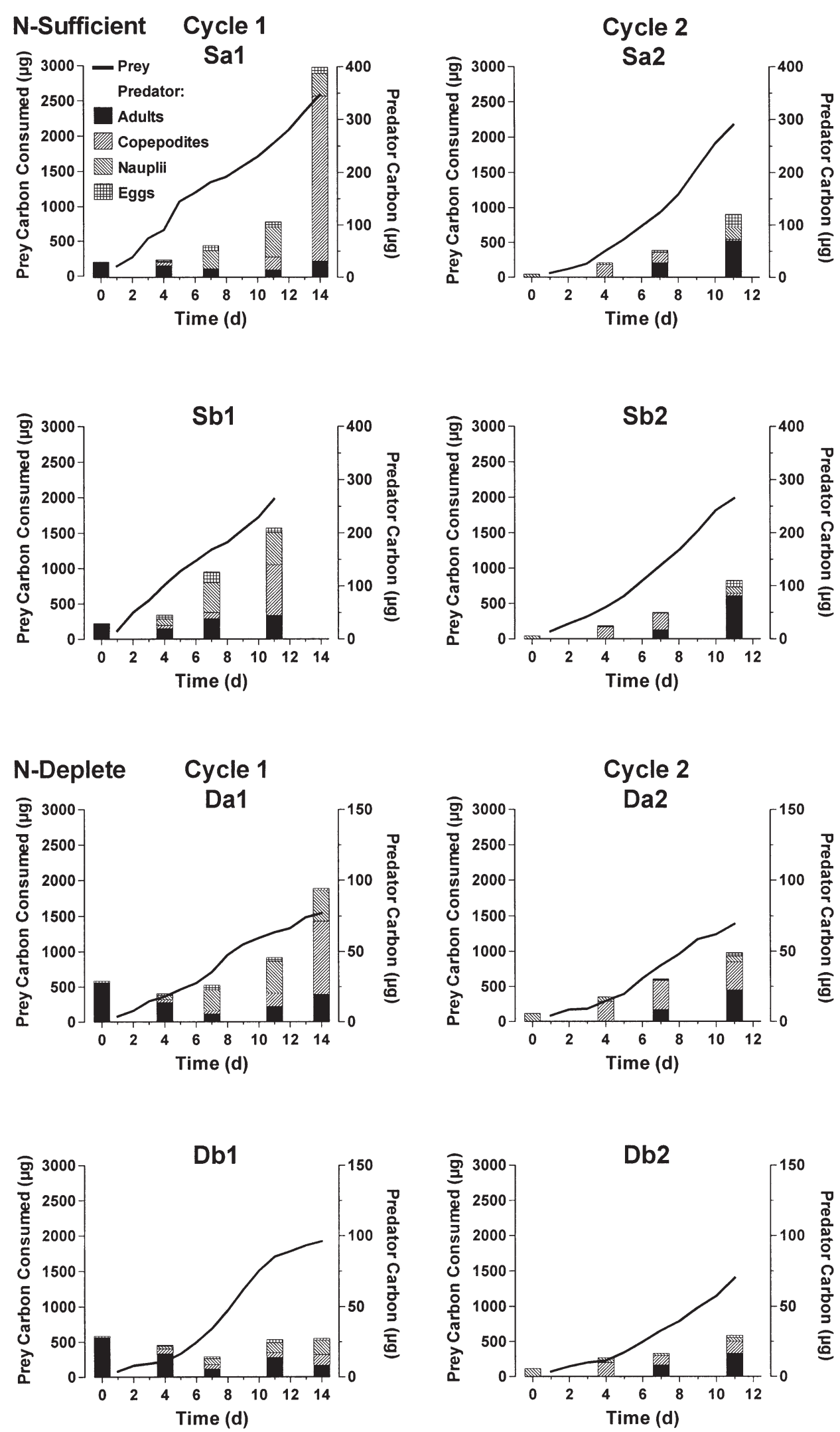

Fig. 6. Change in predator (Acartia tonsa) C biomass plotted together with cumulative total prey C consumed. Note the difference in the $y$-axis scale between $\mathrm{N}$-sufficient and $\mathrm{N}$-deplete treatments 
was also similar to the value of 0.0457 quoted by Kiørboe et al. (1985). Difficulty was experienced in obtaining realistic values for the $\mathrm{C}: \mathrm{N}$ for the eggs and nauplii because of the low biomass of material available for analysis. Literature values for $\mathrm{C}: \mathrm{N}$ values of copepods are highly variable and many values appear implausible (i.e. $\leq 4)$. Values of $\mathrm{C}: \mathrm{N}$ values quoted by Checkley (1980) and Kiørboe et al. (1985) are similar to those we obtained for adult and copepodites. In the absence of evidence to the contrary, we assumed (as did Walve \& Larsson 1999) that C:N values were constant throughout the different developmental stages. We thus averaged all our measurements of $\mathrm{C}$ and $\mathrm{N}$ biomass for adults and copepodites.

The cumulative prey-C consumption with the predator population C-biomass are plotted together in Fig. 6, from which it is clear that not only was growth slower using $\mathrm{N}$-deplete prey but that the PGE was less. The low predator biomass production was not matched pro rata with low prey consumption (note the difference in the $y$-axis scales used for these data). From Fig. 7 it

\section{Carbon Cycle 1}

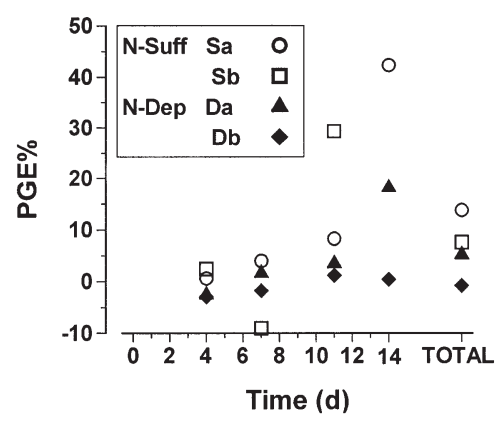

Nitrogen Cycle 1

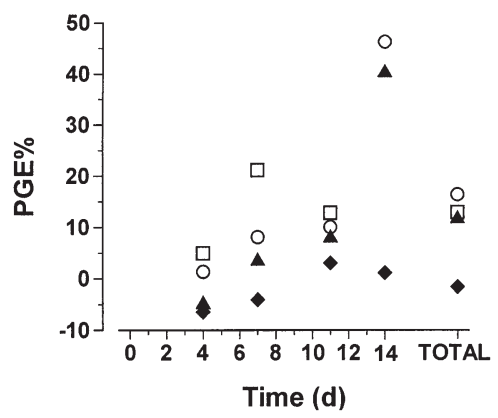

Cycle 2

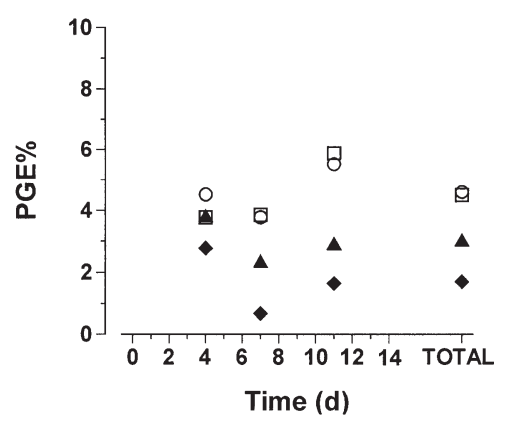

Cycle 2

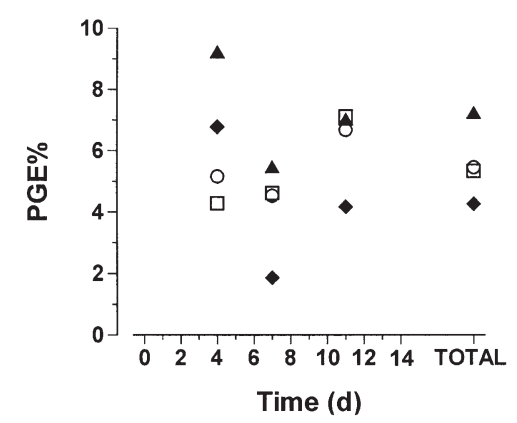

Fig. 7. Acartia tonsa. Population growth efficiencies (PGE) for each predator sampling period. TOTAL: mean for each sampling period can be seen that C-PGE decreased in N-deplete flasks. There was no clear change in N-PGE. There was, however, considerable variation in these estimates of efficiency. The estimates are not robust because the determination of predator biomass from counts of life stages and the biomass values in Table 1 cannot accurately account for the gradual changes in the mass of individuals. This is why we computed growth efficiencies over periods of 3 to $4 \mathrm{~d}$ rather than simply over the whole period of the experimental cycle. Although there was considerable variation in the PGE for individual flasks, the ratios of N-PGE:C-PGE for N-deplete treatments were significantly different (especially in Cycle 2, for which the results are extremely significant; $\mathrm{p}<0.0001$ ) from those for N-sufficient treatments (Fig. 8). N-PGE:C-PGE was about 1 for the $\mathrm{N}$-sufficient flasks and about 2.5 for $\mathrm{N}$-deplete flasks. The initial change in N-PGE:C-PGE at the start of Cycle 1 (Fig. 8) represents the period of change in the prey N:C (cf. Fig. 3). Because there was little mortality in the experimental systems, estimates of GGE and PGE were usually similar (Fig. 9).

\section{DISCUSSION}

Studies of the impact of food on zooplankton nutrition have variously examined the effects of cell size

(Berggreen et al. 1988), prey concentration (Kiørboe et al. 1985), mixtures of different algal species (Kleppel \& Burkart 1995) and elemental (Kiørboe 1989) and biochemical (Kleppel et al. 1998) composition of prey on growth, usually measured as egg production by adults. Nevertheless, the factors that are required in the diet to fully satisfy the nutritional requirements of marine zooplankton remain poorly understood.

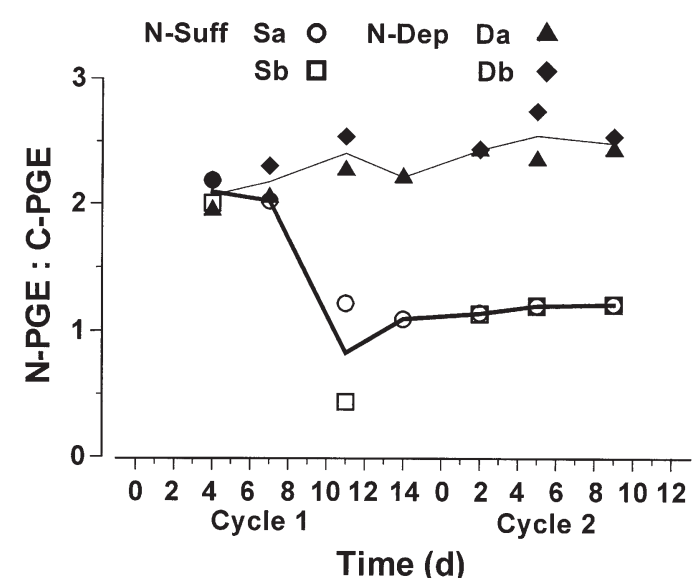

Fig. 8. Acartia tonsa. Ratio of N population growth efficiency: $\mathrm{C}$ population growth efficiency (N-PGE:C-PGE) for all experimental treatments 

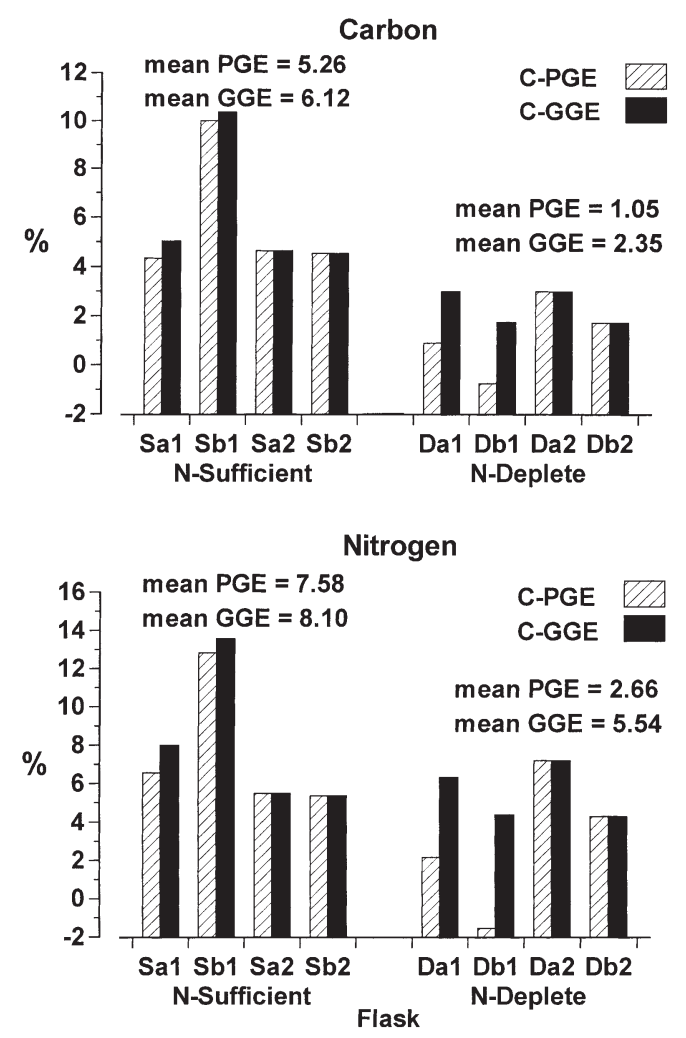

Fig. 9. Acartia tonsa. Growth efficiencies for individual flasks calculated either as population growth efficiency (PGE) or as gross growth efficiency (GGE); see 'Materials and methods'. Means calculated with outliers removed (identified as Flasks Sa1 and Da1, Day 14, using a Grubbs test)

Identification of substrates limiting growth and the efficiency with which they are utilised is important in stoichiometric modelling. Limiting elements are assumed to be used with higher efficiency, with excesses of non-limiting elements being recycled to the environment. The $\mathrm{N}$ content of food has been suggested as a key limiting factor based on observed correlations between egg production and N intake (Checkley 1980, Kiørboe 1989). The presence or absence of specific compounds such as essential amino or fatty acids probably also has an important bearing on nutrition (Kleppel et al. 1998, Anderson \& Pond 2000). Copepods typically consume a diverse diet, ensuring a nutritionally complete ration (Kleppel 1993). The size and morphology of prey are also important through their influence on capture and ingestion (Berggreen et al. 1988). The work here involved laboratory experiments to examine how Acartia tonsa populations respond to mixtures of algal prey supplied under nutrient-sufficient or -deplete conditions. Preference for different species was observed, and intake and production measured in terms of $\mathrm{C}$ and $\mathrm{N}$, permitting the roles of these factors and how they are influenced by algal nutrient status to be simultaneously evaluated.
In our study the prymnesiophyte coccolithophorid Emiliania huxleyi was a major component of the diet of Acartia tonsa under both nutrient-sufficient and nutrient-deplete conditions. This species is commonly available to copepods in temperate and polar waters. Other studies have shown that copepods actively graze E. huxleyi in the laboratory (Harris 1994). Nejstgaard et al. (1997) reported that E. huxleyi can support an unusually high egg production (67 to 81 eggs cope$\operatorname{pod}^{-1} \mathrm{~d}^{-1}$ ) in Calanus finmarchicus. In our study, algal nutrient status influenced the preference between the diatom Thalassiosira weissflogii and the dinoflagellate Aureodinium pigmentosum, the former being favoured under $\mathrm{N}$-sufficient the latter under $\mathrm{N}$-deficient conditions. The dinoflagellate was shown to have a higher $\mathrm{N}$ : $\mathrm{C}$ than the diatom when nutrient-stressed, so this response by $A$. tonsa could be a mechanism to maximise $\mathrm{N}$ intake. In natural systems, it is therefore likely that diatoms are a better food for zooplankton in the early part of the spring bloom than later in the year, after the onset of oligotrophy.

The effect of a varying food $\mathrm{C}: \mathrm{N}$ ratio on egg production in zooplankton was studied by Checkley (1980) and Kiørboe (1989) who fed diatom monocultures to Acartia tonsa. In both cases, production was directly correlated with food N (N-GGE for egg production of $\sim 0.4$ ), suggesting limitation by that element. In our experiments, we similarly found that N-GGE was relatively invariant (suggesting N-limitation), albeit at a lower average value of 0.081 (but estimated over the whole life cycle) with no significant difference between the $\mathrm{N}$-sufficient and $\mathrm{N}$-deplete treatments. Nitrogen GGE was higher than that for C, consistent with the stoichiometric axiom that limiting elements are used most efficiently. Moreover the efficiency of the utilisation of $\mathrm{N}$ relative to $\mathrm{C}$ was highest under N-deplete conditions (Fig. 8), again consistent with N-limitation, and the greatest 'wastage' of $\mathrm{C}$ was associated with high $\mathrm{C}: \mathrm{N}$ food. Our results indicate that growth was strongly correlated with food $\mathrm{N}$ in the experiments involving mixed algal cultures, and that algal nutrient status is therefore important in determining food quality for copepods. In a similar fashion, freshwater Daphnia magna has been shown to have greater growth rates and fecundity when fed on actively growing Chlamydomonas rinhardtii than on $\mathrm{N}$ - or P-limited cells (Mitchell et al. 1992). This alga is normally considered good-quality food, but was not so under nutrient-deplete conditions.

If $\mathrm{N}$ is indeed limiting growth as opposed to being correlated with an alternate limiting factor then, at least according to stoichiometric theory, it should in principle be utilised as efficiently as possible by zooplankton. In theory, $\mathrm{N}$ could be utilised with efficiency near $100 \%$ if catabolic costs could be met with non- 
nitrogenous compounds (Anderson 1992). The low N-GGE of the Checkley (1980) and Kiørboe (1989) egg production experiments led Anderson \& Hessen (1995) to propose that something other than $\mathrm{N}$, but correlated with it, might be limiting. Deficiencies in compounds such as essential fatty acids (EFAs) can be correlated with $\mathrm{N}$ and $\mathrm{P}$ deficiencies in algae (Weers \& Gulati 1997). The potential for limitation by specific biochemicals was investigated using the stoichiometric theory by Anderson \& Pond (2000), who showed that imbalances in EFAs associated with algal monocultures could be enough to override limitation by bulk $\mathrm{C}$ or $\mathrm{N}$ in Calanus helgolandicus. However, in our experiment, limitation by EFAs seems unlikely because we employed mixtures of algae rather than monocultures, and Emiliania huxleyi, which was actively grazed, is known to have high levels of these compounds (Pond \& Harris 1996).

Our study showed that consumption of $\mathrm{N}$-depleted algae retarded not just egg production, but growth throughout the whole life cycle of Acartia tonsa. Similarly, Koski et al. (1998) found that N-limited diatoms led to a dramatic impairment in the development rate of the copepod Pseudocalanus elongatus. Zooplankton life stages are often not distinguished in ecosystem modelling studies. Care must then be exercised to select parameter values that encompass growth and reproduction throughout the life cycle. The work here has shown that growth efficiencies averaged over the whole cycle are considerably lower than egg production efficiencies, the most common measure of GGE. Our study emphasises Straile's (1997) conclusion that the literature on growth efficiencies is not well developed and provides only a few weak generalisations.

A feature of our study is that both GGE and PGE were estimated; PGE may be lower if mortality has occurred. If poor-quality food results in a higher natural mortality, then this will be reflected in PGE but not in GGE. N-deplete algal prey did indeed cause decreased PGE in Acartia tonsa during the early part of the experiment, despite no obvious decrease in GGE (Fig. 9). Further experimentation is required to resolve this issue of efficiency, but clearly the use of GGEs from single phases of the life cycle (such as egg production) gives an inappropriate estimate of whole growth cycle efficiency and is not robust. In addition, there was an obvious difference in the $A$. tonsa population structure when the copepods were fed $\mathrm{N}$-sufficient or $\mathrm{N}$-deplete prey, with those fed $\mathrm{N}$-deplete prey being slower to develop and reproduce, and laying fewer eggs. Models of zooplankton activity and growth should ideally not only distinguish between growth efficiencies associated with different life history stages, but also have variable grazing rates indexed to prey nutrient status.
Acknowledgements. This work was supported by a grant from the Natural Environment Research Council (UK) through the Marine Productivity thematic programme. The valuable contribution of Mrs Betty Griffiths for preparation of algal cultures is gratefully acknowledged.

\section{LITERATURE CITED}

Anderson TR (1992) Modelling the influence of food C:N ratio, and respiration on growth and nitrogen excretion in marine zooplankton and bacteria. J Plankton Res 14: $1645-1671$

Anderson TR, Hessen DO (1995) Carbon or nitrogen limitation in marine copepods? J Plankton Res 17:317-331

Anderson TR, Pond DW (2000) Stoichiometric theory extended to micronutrients: comparison of the roles of essential fatty acids, carbon, and nitrogen in the nutrition of marine copepods. Limnol Oceanogr 45:1162-1167

Berggreen U, Hansen B, Kiørboe T (1988) Food size spectra, ingestion and growth of the copepod Acartia tonsa during development: implications for determination of copepod production. Mar Biol 99:341-352

Checkley DM Jr (1980) The egg production of a marine planktonic copepod in relation to its food supply: laboratory studies. Limnol Oceanogr 25:430-446

Fasham MJR, Ducklow HW, McKelvie SM (1990) A nitrogenbased model of plankton dynamics in the oceanic mixed layer. J Mar Res 48:591-639

Frost BW (1993) A modelling study of processes regulating plankton standing stock and production in the subarctic Pacific Ocean. Prog Oceanogr 32:171-184

Guillard RRL, Ryther J H (1962) Studies on the marine planktonic diatoms. I. Cyclotella nana Husted and Detonela cofervacea (Cleve). Can J Microbiol 8:229-239

Harris RP (1994) Zooplankton grazing on the coccolithophore Emiliania huxleyi and its role in inorganic carbon flux. Mar Biol 119:431-439

Keller MD, Selvin RC, Claus W, Guillard RRL (1987) Media developed for the culture of oceanic ultraphytoplankton. J Phycol 23:633-638

Kiørboe T (1989) Phytoplankton growth rate and nitrogen content: implications for feeding and fecundity in a herbivorous copepod. Mar Ecol Prog Ser 55:229-234

Kiørboe T, Møhlenberg F, Hamburger K (1985) Bioenergetics of the planktonic copepod Acartia tonsa: relation between feeding, egg production and respiration, and composition of specific dynamic action. Mar Ecol Prog Ser 26:85-97

Kleppel GS (1993) On the diets of calanoid copepods. Mar Ecol Prog Ser 99:183-195

Kleppel GS, Burkart CA (1995) Egg production and the nutritional environment of Acartia tonsa: the role of food quality in copepod nutrition. ICES J Mar Sci 52:297-304

Kleppel GS, Burkart CA, Houchin L (1998) Nutrition and the regulation of egg production in the Calanoid copepod Acartia tonsa. Limnol Oceanogr 43:1000-1007

Koski M, Klein Breteler W, Schogt N (1998) Effect of food quality on rate of growth and development of the pelagic copepod Pseudocalanus alongatus (Copepoda, Calanoida). Mar Ecol Prog Ser 170:169-187

Miralto A, Barone G, Romano G, Poulet SA and 7 others (1999) The insidious effect of diatoms on copepod reproduction. Nature 402:173-176

Mitchell SF, Trainor FR, Rich PH, Goulden CE (1992) Growth of Daphnia magna in the laboratory in relation to the nutritional state of its food species, Chlamydomonas rinhardtii. J Plankton Res 14:379-391 
Nakano SI (1994) Carbon:nitrogen:phosphoros ratios and nutrient regeneration of a heterotrophic flagellate fed on bacteria with differential elemental ratios. Arch Hydrobiol 129:257-271

Nejstgaard JC, Gismervik I, Solberg PT (1997) Feeding and reproduction by Calanus finmarchicus, and microzooplankton grazing during mesocosm blooms of diatoms and the coccolithophore Emiliania huxleyi. Mar Ecol Prog Ser 147:197-217

Parsons TR, Takahashi M, Hargrave B (1984) Biological oceanographic processes. Pergamon Press, Oxford

Pond D, Harris RP (1996) The lipid composition of the coccolithophore Emiliania huxleyi and its possible ecophysiological significance. J Mar Biol Assoc UK 76:570-594

Poulet SA, Ianora A, Miralto A, Meijer L (1994) Do diatoms arrest embryonic development in copepods? Mar Ecol Prog Ser 111:79-86

Sterner RW, Hessen DO (1994) Algal nutrient limitation and the nutrition of aquatic herbivores. Annu Rev Ecol Syst 25:1-29

Støttrup JG, Jensen J (1990) Influence of algal diets on feed-

Editorial responsibility: Otto Kinne (Editor),

Oldendorf/Luhe, Germany ing and egg-production of the calanoid copepod Acartia tonsa Dana. J Exp Mar Biol Ecol 141:87-105

Straile D (1997) Gross growth efficiencies of protozoan and metazoan zooplankton and their dependence on food concentration, predator-prey weight ratio, and taxonomic group. Limnol Oceanogr 42:1375-1385

Tang KW, Dam HG (1999) Limitation of zooplankton production: beyond stoichiometry. Oikos 84:537-542

Walve J, Larsson U (1999) Carbon, nitrogen and phosphorus stoichiometry of crustacean zooplankton in the Baltic Sea: implications for nutrient recycling. J Plankton Res 21: 2309-2321

Weers PMM, Gulati RD (1997) Growth and reproduction of Daphnia galeata in response to changes in fatty acids, phosphorus, and nitrogen in Chlamydomonas reinhardtii. Limnol Oceanogr 42:1584-1589

Wood GJ, Flynn KJ (1995) Growth of Heterosigma carterae (Raphidophyceae) on nitrate and ammonium at 3 photon flux densities: evidence for $\mathrm{N}$ stress in nitrate-growing cells. J Phycol 31:859-867

Submitted: October 8, 2001; Accepted: December 20, 2001 Proofs received from author(s): May 13, 2002 